\title{
Editorial: Changes in Forest Ecosystem Nutrition
}

\author{
Friederike Lang ${ }^{1 *}$, Jaane Krüger ${ }^{1}$, Klaus Kaiser ${ }^{2}$, Roland Bol ${ }^{3,4}$ and \\ Sebastian Loeppmann ${ }^{5,6}$ \\ ${ }^{1}$ Chair of Soil Ecology, Faculty of Environment and Natural Resources, University of Freiburg, Freiburg, Germany, ${ }^{2}$ Soil \\ Science and Soil Protection, Martin Luther University Halle-Wittenberg, Halle, Germany, ${ }^{3}$ Research Centre Jülich, Institute of \\ Bio- and Geosciences, Agrosphere (IBG-3), Jülich, Germany, ${ }^{4}$ School of Natural Sciences, Bangor University, Bangor, \\ United Kingdom, ${ }^{5}$ Biogeochemistry of Agroecosystems, Georg-August-University, Göttingen, Germany, ${ }^{6}$ Department of Soil \\ Science, Institute of Plant Nutrition and Soil Science, Christian-Albrechts-University, Kiel, Germany
}

Keywords: phosphorus, nitrogen, cross-scale nutritional interactions, nutrient use efficiency, disturbance, scales of ecosystem nutrition

\section{Editorial on the Research Topic}

\section{OPEN ACCESS}

\section{Edited and reviewed by:} Frank Hagedorn,

Swiss Federal Institute for Forest, Switzerland

*Correspondence:

Friederike Lang

fritzi.lang@

bodenkunde.uni-freiburg.de

Specialty section:

This article was submitted to Forest Soils,

a section of the journal Frontiers in Forests and Global

Change

Received: 02 August 2021 Accepted: 05 August 2021 Published: 30 August 2021

Citation:

Lang F, Krüger J, Kaiser K, Bol R and Loeppmann S (2021) Editorial: Changes in Forest Ecosystem

Nutrition.

Front. For. Glob. Change 4:752063. doi: 10.3389/ffgc.2021.752063

\section{Changes in Forest Ecosystem Nutrition}

Forests strongly depend on natural nutrient resources since fertilization is not a common forest management practice in most parts of the world. Soils and above- and belowground interactions play a crucial role in regulating the retention, distribution, and uptake of nutrients. The high relevance of nutrition for health and productivity of forests has been demonstrated by recent research data obtained by extensive forest monitoring around the world. For example, nutrient availability was the most decisive factor explaining net forest ecosystem productivity (NEP) for a global population of 92 forest sites (Fernández-Martínez et al., 2014). Also, changes in phosphorus $(\mathrm{P})$ and nitrogen $(\mathrm{N})$ nutrition have been emphasized in recent studies on European forests (Jonard et al., 2015; Etzold et al., 2020). These findings stress the necessity of addressing forest nutrition via holistic ecosystem approaches (Figure 1), as was recently outlined for P (Lang et al., 2016).

Linking trees' nutrient supply with the abundance and activity of other organisms present in different ecosystem compartments has a long tradition in forest-related research. Thus, vast information on relationships between soils and site conditions, nutrient cycling and composition, and productivity of vegetation has been collected systematically over long periods of time, and then used to develop empirical models of forest growth (e.g., Barnes et al., 1982). However, forest ecosystem interactions are exposed to quickly changing environmental conditions. Recent drivers of forest nutrition include (a) higher global atmospheric $\mathrm{N}$ deposition leading to increased productivity (Etzold et al., 2020) and causing nutrient imbalances (Peñuelas et al., 2012); (b) climate change affecting the recycling of nutrients (Medlyn et al., 2011) and increasing forest disturbance (Gleason et al., 2010); or (c) changes in management intensity leading to increased removal of nutrients with biomass (Vadeboncoeur et al., 2014). Such changes in nutritional conditions are expected to translate into detrimental effects on forest ecosystems. Therefore, proper management of forests for preserving their functioning requires timely updating of empirical knowledge about ecosystem interactions and their feedbacks to nutrition. 


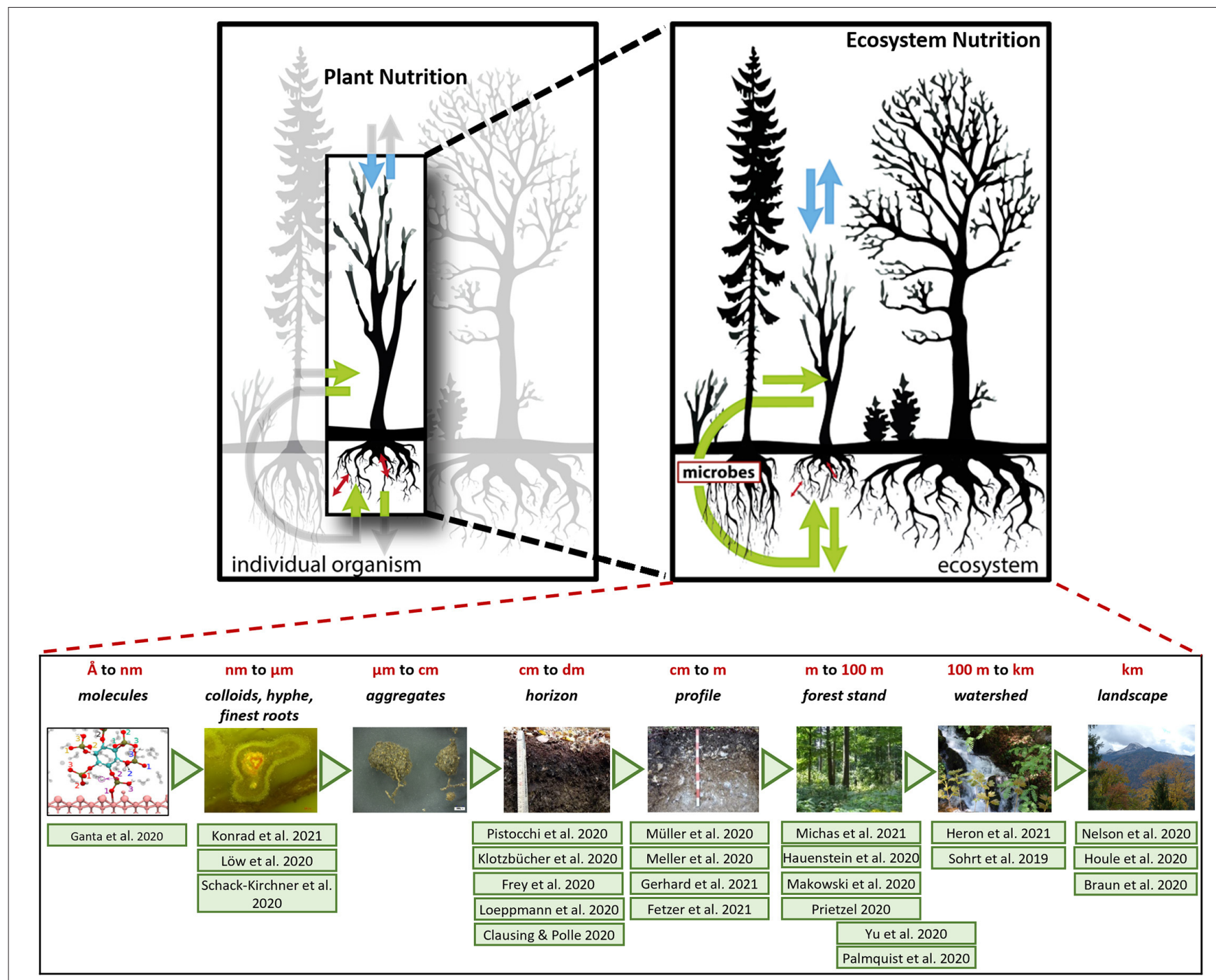

FIGURE 1 | In contrast to plant nutrition, which focuses on individual target plants, ecosystem nutrition covers all ecosystem compartments and their interactions (Top). The different articles within the Research Topic Changes in Forest Ecosystem Nutrition address manifold compartments and interactions on a wide range of spatial scales (Bottom).

Many new approaches of ecosystem nutrition have been compiled in the Research Topic "Changes in Forest Ecosystem Nutrition," covering spatial scales (Figure 1) from the molecular level (Ganta et al.) up to landscapes (Houle et al.). Those approaches are complementary to the traditional concepts of plant nutrition, which focus on one-way relationships between soil and plants. Key factors in P ecosystem nutrition at discrete scale levels were $\mathrm{P}$ speciation in soils (Klotzbücher et al.; Konrad et al.), nutrient mobilization by root exudates (Schack-Kirchner et al.), microbial (Michas et al.), and fungal communities (Müller et al.), identification of $\mathrm{P}$ sources and uptake processes (Pistocchi et al.; Hauenstein et al.), P-efficiency of mycorrhizal fungi (Clausing and Polle), the impact of beech provenances (Meller et al.) and root surface distribution (Loew et al.). The topic also addresses factors effective along different scale levels, such as P leaching within soils (Makowski et al.; Gerhard et al.;
Fetzer et al.) or at catchment scale (Sohrt et al.), element coupling during microbial non-steady state conditions at profile scale (Loeppmann et al.) or stand scale (Palmqvist et al.), and $\mathrm{P}$ heterogeneity at stand scale (Prietzel) and at the scale of landscapes (Yu et al.). In addition, the topic extents to the impact of certain drivers of ecosystem nutrition, including land-use (Heron et al.), pedogenetic and ecosystem succession (Nelson et al.), climate change (Houle et al.) and of $\mathrm{N}$ deposition (Braun et al.; Frey et al.).

Overall, the range of publications in the Research Topic impressively illustrates that plant nutrition approaches considering only processes immediately relevant to vitality and yield of individual plants are not sufficient to address recent challenges linked to human impact on forest ecosystems. The importance of saprophytic symbiotic microorganisms including their community composition, abundance, and activity 
- for nutrient turnover in forest ecosystems, and the linkages between above- and below-ground biota, as well as relations to ecosystem services need to be carefully considered. At the scale of ecosystems, heterogeneity and its structuring effects, seasonality, and links to nutrient transport by soil water or within organisms, become crucial factors. Based on the compiled studies, we postulate that for understanding their resilience against and vulnerability to global change, ecosystem nutrition processes need to be characterized based on their emergent interacting, hierarchy, spatial and temporal structure, and robustness. Sound evaluation of the human impact on forest ecosystem nutrition needs assessment beyond nutrient budgets and contents, by considering all relevant key factors that link mobilization and immobilization processes, and therefore shape the nutrient use efficiency of forests at the ecosystem level.

\section{REFERENCES}

Barnes, B. V., Pregitzer, K. S., Spies, T. A., and Spooner, V. H. (1982). Ecological forest site classification. J. Forestry 80, 493-498.

Etzold, S., Ferretti, M., Reinds, G. J., Solberg, S., Gessler, A., Waldner, P., et al. (2020). Nitrogen deposition is the most important environmental driver of growth of pure, even-aged and managed European forests. Forest Ecol. Manage. 458:117762. doi: 10.1016/j.foreco.2019.117762

Fernández-Martínez, M., Vicca, S., Janssens, I. A., Sardans, J., Luyssaert, S., Campioli, M., et al. (2014). Nutrient availability as the key regulator of global forest carbon balance. Nature Climate Change 4:471-476. doi: $10.1038 /$ nclimate 2177

Gleason, S. M., Read, J., Ares, A., and Metcalfe, D. J. (2010). Species-soil associations, disturbance, and nutrient cycling in an Australian tropical rainforest. Oecologia 162, 1047-1058. doi: 10.1007/s00442-009-1527-2

Jonard, M., Fürst, A., Verstraeten, A., Thimonier, A., Timmermann, V., Potočić, N., et al. (2015). Tree mineral nutrition is deteriorating in Europe. Global Change Biol. 21, 418-430. doi: 10.1111/gcb.12657

Lang, F., Bauhus, J., Frossard, E., George, E., Kaiser, K., Kaupenjohann, M., et al. (2016). Phosphorus in forest ecosystems: New insights from an ecosystem nutrition perspective. J. Plant Nutr. Soil Sci. 179, 129-135. doi: 10.1002/jpln.201500541

Medlyn, B. E., Duursma, R. A., and Zeppel, M. J. B. (2011). Forest productivity under climate change: a checklist for evaluating model studies. WIREs Clim. Change 2, 332-355. doi: 10.1002/wcc.108

\section{AUTHOR CONTRIBUTIONS}

FL prepared the draft. JK compiled the figures. RB, $\mathrm{SL}$, and $\mathrm{KK}$ revised the draft. All authors approved the final submission.

\section{ACKNOWLEDGMENTS}

The idea for this Research Topic resulted from the discussion within the Priority Programme 1685 Ecosystem Nutrition-Forest strategies for limited phosphorus resources funded by the German Research Foundation (DFG). We greatly thank all authors and reviewers for their contributions to this special issue as well as the support of the editorial office.

Peñuelas, J., Sardans, J., Rivas-ubach, A., and Janssens, I. A. (2012). The humaninduced imbalance between C, N and P in Earth's life system. Global Change Biol. 18, 3-6. doi: 10.1111/j.1365-2486.2011.02568.x

Vadeboncoeur, M. A., Hamburg, S. P., Yanai, R. D., and Blum, J. D. (2014). Rates of sustainable forest harvest depend on rotation length and weathering of soil minerals. Forest Ecol. Manage. 318, 194-205. doi: 10.1016/j.foreco.2014.01.012

Conflict of Interest: The authors declare that the research was conducted in the absence of any commercial or financial relationships that could be construed as a potential conflict of interest.

Publisher's Note: All claims expressed in this article are solely those of the authors and do not necessarily represent those of their affiliated organizations, or those of the publisher, the editors and the reviewers. Any product that may be evaluated in this article, or claim that may be made by its manufacturer, is not guaranteed or endorsed by the publisher.

Copyright (c) 2021 Lang, Krüger, Kaiser, Bol and Loeppmann. This is an open-access article distributed under the terms of the Creative Commons Attribution License (CC $B Y)$. The use, distribution or reproduction in other forums is permitted, provided the original author(s) and the copyright owner(s) are credited and that the original publication in this journal is cited, in accordance with accepted academic practice. No use, distribution or reproduction is permitted which does not comply with these terms. 